\title{
The CS- effect in simple conditioning and stimulus selection during development
}

\author{
NORMAN E. SPEAR, DAVID KUCHARSKI, and JAMES S. MILLER \\ State University of New York at Binghamton, New York
}

\begin{abstract}
Changes in affect toward a particular stimulus can take place very rapidly through Pavlovian conditioning, if presentation of the conditioned stimulus (CS+) paired with the unconditioned stimulus (US) is accompanied by presentation of a "CS - ," another value of the same dimension as the CS+ but not paired with a US. This effect has considerable generality. It has been observed in terms of both olfactory and visual CSs, in terms of appetitive as well as aversive conditioning, and for adult as well as infant rats. The CS - effect has seemed especially important for infants, which may be related to the general tendency for infants to exhibit less stimulus selection than older animals. Finally, the CS - effect has enabled the development of a simple test of shortterm retention that can quite effectively assess memory for either incidental or target events. These tests so far have indicated a clear ontogenetic decrease in rate of forgetting over short intervals, corresponding to the well-known development-related decrease in forgetting over long intervals (infantile amnesia). The tests also have shown that short-term forgetting of intentional and target events is surprisingly similar, with some indication of more rapid forgetting for the incidental events. Alternative interpretations of the CS- effect and some preliminary tests of these interpretations are discussed.
\end{abstract}

During the first three weeks of the developing rat's postnatal life, there are dramatic changes in motor coordination and sensory capacities. Structural and neurochemical changes in the brain are equally dramatic. For instance, by the age of 2 weeks postnatal the rat will have undergone immense change from the hairless, relatively helpless neonate it once was, to a capable, well-coordinated animal with all sensory systems reasonably active; yet even at this point the number of neocortical synapses in this rat will increase further, by 5-10 times their present number within their next week or two of growth. Throughout this period of rapid postnatal growth, the rat is, from Day 1 on, a quite adaptive creature, capable of substantial learning (for reviews, see Kail \& Spear, 1984; Spear \& Campbell, 1979). In this paper, we review some issues associated with a simple procedure that can substantially affect a general instance of rapid learning that is prevalent in the developing rat.

A question we have been pursuing for some time is why these very young rats, like very young people, show infantile amnesia-exaggerated forgetting for events of their infancy over a long interval that includes a period of their growth. What makes this forgetting exaggerated is that

Presented at the Seventh Harvard Symposium on Quantitative Analyses of Behavior: Biological Determinants, Harvard University, June 8-9, 1984. This research was supported by a grant from the National Institute of Mental Health (1 RO1 MH35219) to Norman Spear. The authors would like to express their appreciation to Norman G. Richter for his technical assistance, and to Teri Tanenhaus for preparation of the manuscript. Norman E. Spear and James S. Miller wish to acknowledge the contributions of the late David Kucharski to the present paper. Requests for reprints should be addressed to Norman E. Spear, Department of Psychology, SUNY Binghamton, Binghamton, NY 13901. it exceeds adult forgetting: under the same circumstances, forgetting may be essentially complete for infants within a few days, but not for adults until many days or even weeks later (see, e.g., Campbell \& Spear, 1972; Markiewicz, Kucharski, \& Spear, 1986). What makes it interesting is that this age-related difference in rate of forgetting occurs even when the degrees of learning have been equivalent. Equivalent learning by rats of different ages is not always easy to achieve, due to age-related differences that may occur in rates of learning. It is these learning differences that we address here.

It has been the rule historically that relative to adults, preweanling animals have seemed to be deficient in their rates of learning as well as in remembering. There are good reasons why the adjective "deficient" is inappropriate, however, for describing the behavior of infants in comparison with that of adults (for convenience in this paper we use the term "infant" for rats younger than 21 days postnatal). The observation that infants learn adult tasks slowly does not necessarily imply that infants are deficient learners. The "deficiency" frequently declines or disappears entirely when tasks are designed with infants in mind and take into account the ecological circumstances for which the infant rat is especially adapted, and in some circumstances, infants learn more rapidly than older rats (Spear, Kraemer, Molina, \& Smoller, 1988; Spear \& Molina, 1987). In this paper, we emphasize simple memory tests designed to accommodate both infants and adults. The issues and data we discuss have implications that reach beyond the course of development, however, and some relevance to learning and memory in general. 


\section{Ontogenetic Differences in What Is Learned}

One of our earlier hypotheses about infantile amnesia was that the memory capacity of the infant rat is limited by its underdeveloped brain, which in turn limits the number of redundant or irrelevant features the infant learns about a conditioning episode (Spear, 1979). We thought that the memory advantage held by the adult was due to the adult's greater learning of incidental or irrelevant events. This extra learning could provide extra retrieval routes to the target memory. We have since rejected this hypothesis. Our tests have indicated that preweanling rats do not learn fewer incidental or irrelevant events than adults. Instead, they behave as if they had learned more of these events than adults. The facts simply forced a change in our ideas.

The alternative we have taken is that ontogenetic differences in learning and memory do not primarily reflect differences in basic capacity for learning or memory. What is typically registered as inferior learning on the part of younger animals is instead more a matter of what they learn. What they learn, we have discovered, is different from what older animals learn. We could refer to this as "age-related differences in attention." Generally, however, presumed attentional differences have instead often been shown to be a matter of associative learning or memory retrieval (e.g., Rescorla \& Wagner, 1972; Spear, 1978; Wagner, 1981). We therefore prefer the more neutral term, stimulus selection. This approach has some advantages. For instance, dealing with ontogenetic differences in stimulus selection rather than in capacity allows for the occasional instances of greater learning by preweanling than by adult rats (Spear, 1984b; Spear et al., 1988; Spear \& Molina, 1987).

Immature animals have seemed to be less selective than adults in what they learn. For example, preweanlings respond more to redundant contexts and usually show less blocking, less overshadowing, and more potentiation than adults. One interpretation of these results is that the younger animal processes information from irrelevant or incidental features of the conditioning episode more fully. In other words, infants are more likely to learn about less "salient" events and about those less closely linked, by contingency, with the strong stimuli we call reinforcers. They seem to deal with the components of multiple-event stimuli less exclusively than do adults. In the cases of blocking and overshadowing, learning of the "nontarget" components is less likely reduced for the infant by learning of the target (Caza, 1984; Kraemer, Lariviere, \& Spear, 1988; Spear \& Kucharski, 1984a, 1984b); for potentiation, the nontarget component is more likely to facilitate learning of the target among infants (Hinderliter \& Misanin, 1988; Kucharski \& Spear, 1985; Spear \& Kucharski, 1984a, 1984b); and when context (redundant by definition) is changed, the learned performance of infants suffers more than that of adults (Solheim, Hensler, \& Spear, 1980).
Caution is still required as to the general applicability of these effects. Relatively few sensory modalities have been represented in tests of these effects to date. In other respects as well, the picture of ontogenetic differences in stimulus selection is not as clear as this summary might imply. For instance, these basic tests of stimulus selection require that the animals process stimulus compounds, sets of several stimuli usually presented simultaneously. Our recent data have indicated that in this situation the younger animal has a greater tendency than adults toward stimulus configuration (Kucharski \& Spear, 1985; Spear \& Kucharski, 1984a, 1984b). To the extent that the animal engages in what has been termed "integral processing" (Garner, 1974), treating perceptually a set of two stimuli as one glob rather than as two discrete events, the issue of stimulus selection is secondary. At the present time, however, the facts are most easily described by reference to an ontogenetic increase in stimulus selection.

One of the first lessons that we learned in testing the memory of infant animals was to keep the tasks simple and consistent with the ecological challenges that are characteristic for the infant rat. We deal with very elementary learning tests. Our experimental paradigms typically include a footshock, induced illness, or a nutrient paired with a particular odor, taste or tactile stimulus; changes in preference for these conditioned stimuli are measured. After the first two weeks of life, when the rat's eyes and ears are fully open, we may also test learning about the brightness and/or location of a particular compartment or about the pitch of a tone. In the present paper we emphasize Pavlovian conditioning experiments, with footshock as the unconditioned stimulus (US). Age-related differences in aversion thresholds to footshock are minor and readily controlled experimentally (Campbell, 1967; Collier \& Bolles, 1979).

\section{Preliminary Neurophysiological Analysis of the Ontogeny of Stimulus Selection}

The physiological basis of the ontogenetic increase in stimulus selection may be assessed in a number of ways. One approach is to ask whether the neurochemical systems that monitor stimulus selection in the adult are fully functional in the preweanling. This approach was taken by Patricia Caza in her PhD dissertation in our laboratory (Caza, 1984). Proceeding from the prevalent notion that norepinephrine is important for stimulus selection, in her initial experiment Caza compared the influence of a beta-adrenergic agonist, isoproterenol (which would mimic the action of norepinephrine), on blocking and overshadowing in rats 15,30 , or 60 days old (adults). The conditioned stimuli (CSs) were odors and brightnesses. For blocking, the animal first learned that black was paired with footshock, then had a distinctive odor combined with black and paired with footshock. The question was how much was learned about the odor. For the test of overshadowing or potentiation, black was com- 
pounded with one distinctive odor and white with another, and the question was how much was learned about the odor, in comparison with groups for which the different brightnesses were not presented. These tasks are like those we shall emphasize later in this paper.

Caza's tests with this agonist and with complementary antagonists gave support to the notion that ontogenetic increases in blocking could be mediated in part by noradrenergic transmission. The results were by no means simply interpreted, however, and Caza ultimately concluded that the noradrenergic influence of norepinephrine on stimulus selection is governed by an inverted- $U$ function.

Another approach to the physiological basis of the ontogeny of stimulus selection is to ask whether particular brain structures important for stimulus selection in adults are functionally immature in the preweanling. The hippocampus may be such a structure. This is suggested by indications that the stimulus-selection behavior of a hippocampectomized adult is similar to that of an intact preweanling with a hippocampus that is immature in anatomical and other respects. For example, we have found that just as intact infants, adult rats with hippocampal lesions show relatively little overshadowing (Schmajuk, Spear, \& Isaacson, 1983; using a different index of conditioning, Garrud et al., 1984, obtained a different result).

Preweanling rats given a compound of two different tastes or two different odors not only show less overshadowing than adults, they tend toward the opposite effect: potentiation. In other words, it is as if the preweanling learns more about a particular taste or odor if it is paired with another taste or odor than if it is presented alone. In these situations, older animals show overshadowing, no effect of the "extra" stimulus element, or at most, weak potentiation (Kucharski \& Spear, 1985; Spear \& Kucharski, 1984a, 1984b). Together with Robert L. Isaacson and Joseph Springer, we tested potentiation in adults given hippocampal lesions, cortical lesions, or sham lesions. The task was another simple one. The animals tasted a stimulus compound of coffee mixed with sucrose, which was followed by an injection of $\mathrm{LiCl}$. These details and other procedures were the same as those we had used with the preweanling rats (Kucharski \& Spear, 1985). They included feeding rats the CS solution "by hand" through a blunted syringe, which provides good control over temporal characteristics of the CS and its magnitude. The results are shown in Figure 1. This case of potentiation in the hippocampal animals-significantly greater than for the controls-is like the effect we see in the preweanling and unlike that in normal adults. Enhanced potentiation in rats with hippocampal lesions has also been observed by Miller, Nonneman, Kelly, Neisewander, and Isaac (1986).

What we can make of the similarity between these hippocampally linked effects and the similar effects observed in infants is quite another issue; we are of course not suggesting that the infant rat is like a brain-damaged adult. Yet the similarities are intriguing with respect to the ontogenetic issue of the presence as opposed to the

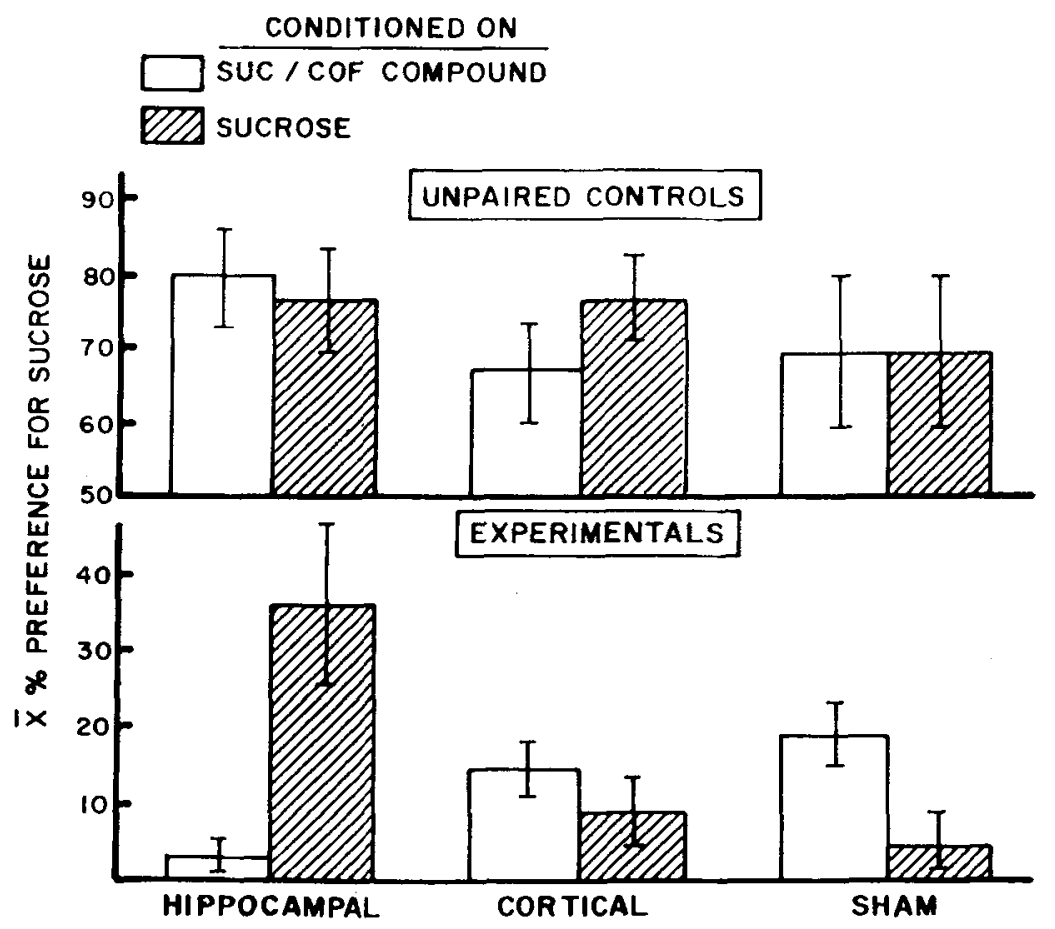

Figure 1. Mean percent preference for sucrose (sucrose intake/sucrose intake + water intake) for experimental and control groups, as a function of conditioning solution and lesion. 
absence of a functional hippocampus (for a systematic set of other similarities, see Amsel, 1986; Amsel \& Stanton, 1980).

The physiological basis of the ontogeny of learning and stimulus selection often enters into considerations of certain apparently invariant dispositions of animals for associating particular conditioned stimuli (CS) with particular unconditioned stimuli (US). The preweanling rat may have a peculiar set of such dispositions, unlike that of the adult. For instance, we have found that when visual and olfactory characteristics of the conditioning context are less novel-more like their home nest-the preweanling learns more about stimuli that predict peripheral footshock but less about stimuli that predict internal toxicosis. We have found no such effects in adult animals (see, e.g., Infurna, Steinert, \& Spear, 1979; Smith \& Spear, 1978; for a review and recent evidence, see Spear, Kucharski, \& Hoffmann, 1985). Very young infants also seem more likely than older ones to express a conditioned aversion to a taste that has been paired with footshock (Hoffmann \& Spear, 1988).

Other associative dispositions, however, might be common to the preweanling and adult. For instance, Haroutunian and Campbell (1979) found that rats as young as 2-4 days of age readily acquired an association between a puff of a novel odor and either toxicosis from $\mathrm{LiCl}$ or an electrical shock delivered to the gut. The association between that same odor and a footshock, however, seemed not to be acquired convincingly with the same procedures until the rat was nearly 2 weeks of age. This surprising infantile "deficit" in conditioning with odor-footshock pairing provides the point of departure for the bulk of the present paper.

The question that arises is why the neonatal and infant rat should have such difficulty in associating odors and footshock. Neonates are known to process odors quite effectively, beginning prenatally and continuing from birth onward. There is also a good deal known about controlling ontogenetically the perceived intensity of footshock, mentioned earlier as one reason for its frequent use as an unconditioned stimulus in these studies, and footshock is aversive to the rat pup from the first few days of life. In spite of this, is it impossible for them to associate odors and footshock until much later?

It is at this point that we begin to deal directly with the "CS -" referred to in the title. By "CS-" we mean, operationally, a stimulus on the same sensory dimension as the CS +: whereas the CS+ is paired with the US, the CS - is explicitly not paired with the US. We suspected that if the rat pups in the Haroutunian and Campbell (1979) study had been presented a CS - , evidence of conditioning an odor to a footshock would have been observed at earlier ages.

\section{The CS- Effect}

That a CS - might aid CS + conditioning was interesting to us, because we had a prediction in mind, based on the ontogeny of stimulus selection. We thought a CSshould especially help CS + conditioning in infant and preweanling animals. Although not tested systematically with Pavlovian conditioning, there seemed a consensus that what an $\mathbf{S}$ - does in operant discrimination learning is to help the animal sort out redundant and irrelevant stimuli from the $\mathbf{S}+$, the best predictor of the reinforcer (see, e.g., Mackintosh, 1974). Applying this to Pavlovian conditioning, we expected that the CS - would benefit $\mathrm{CS}+$ conditioning more in younger animals because of their special "problem" in sorting out the incidental from the critical events (Spear, 1984b).

We had a reason for being puzzled by the Haroutunian and Campbell (1979) result. Several years before this result was published, Richard Bryan (1979) had begun an extensive $\mathrm{PhD}$ dissertation in our laboratory, testing the characteristics of an odor aversion conditioned by pairing the odor with footshock. All of his several experiments tested the 7-day-old rat, with conditioning readily achieved using only one fifth as many conditioning trials as were used by Haroutunian and Campbell. Bryan's procedures, worked out on the basis of intuition and empirical confirmation, included a CS - as well as a CS + . By this we mean that the rat was exposed to both a particular odor paired with a footshock and another odor (the $\mathrm{CS}-$ ) in the absence of footshock. Haroutunian and Campbell had not used a CS- .

The issue of why 7-day-old rats were readily conditioned with his procedures was not dealt with in Bryan's study; instead, the final product (Bryan, 1979) reported more than 30 experiments to explain why distributed practice facilitated retention in these animals. Bryan was aware that there was nothing particularly innovative about the inclusion of a CS - in his procedures. It is fairly common for investigators to include a CS - along with a CS + in such affective conditioning procedures, because this simply has seemed to yield the most effective conditioning. The question reviewed in the present paper is whether this is really so, and why.

We first tested the effect of a CS - by using ages, odors, and footshocks similar to those used by Haroutunian and Campbell (1979), although the conditioning procedure itself was more like that used by Bryan (1979). On each trial, exposure to the CS - odor was given in a small, Plexiglas, rectangular compartment for $20 \mathrm{sec}$; exposure to the CS + occurred in another compartment and was identical to the CS - exposure except that it included a different odor and two footshocks (during Seconds 8-10 and 18-20). Testing of aversion to the CS + was relative to a third odor, not the CS - , and took place in a different, longer apparatus, which held the alternative odorants at each end. Aversion was assessed in terms of the rat's spatial location during a period of a few minutes. It is important that all of our tests of CS + aversion compare preference for the CS + and a novel odor-not the CS - . The effect of the CS - is explicitly restricted to conditioning, because the $\mathrm{CS}-$ is not present during the test.

The results were pretty much as we had expected. Given presentation of the CS-, odor-footshock conditioning was quite effective in pups as young as 6 days of age, with as few as two conditioning trials (see Figure 2). 


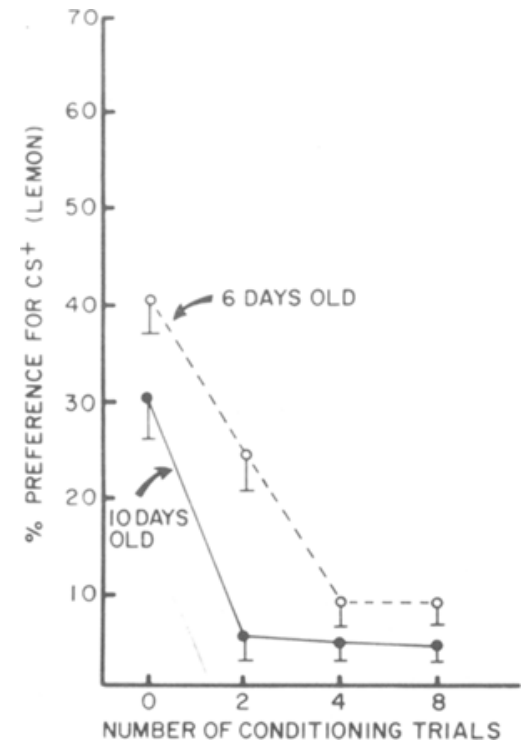

Figure 2. Mean percent preference for lemon (time spent over lemon/time spent over lemon + time spent over banana), as a function of age and number of conditioning trials (adapted from Kucharski \& Spear, 1984).

Haroutunian and Campbell (1979) had found no conditioning in rats nearly twice as old, with 15 times as many conditioning trials; but they had not used a CS-.

We next tested the relative efficacy of procedures with and without a CS - for odor-footshock conditioning among rats either 8,15 , or 50 days old (Kucharski \& Spear, 1984). For some animals, an explicit CS - , a novel odor not paired with footshock, preceded the CS + . For two other sets of animals of each age, there was no exposure to this $\mathrm{CS}-$. These rats were exposed instead either to their home nest shavings or to clean shavings. The idea was to place these control animals where they would be unlikely to smell a novel odor, but otherwise to treat them the same as rats given the $\mathrm{CS}-$. Within each age group, rats were given either 0,1 , or 8 trials with one of these three conditioning procedures.

For the 8-day-old animals given a CS-, conditioning was quite effective with 8 conditioning trials, but no aversive conditioning of the CS+ occurred without exposure to the CS - (Figure 3). For the 15- and 60-dayold animals given a single pairing of the $\mathrm{CS}+$ and US, the same effect occurred-greater conditioning with the CS - than without it. Given enough training, however, these older animals did show some conditioning without the CS - (Figures 4 and 5). In summary, conditioning with the youngest rats seemed to benefit most from the CS - , but this was not a particularly robust difference ontogenetically.

More compelling evidence for age-related differences in the influence of $\mathbf{C S}$ - on stimulus selection is provided by a subsequent series of experiments (J. S. Miller, Jagielo, \& Spear, in press), in which marked ontogenetic differences in the enhancement of single-trial conditioning by $\mathrm{CS}-$ were observed. Odor-conditioning treatments were similar to those described earlier except that, in order to increase the likelihood of obtaining one-trial conditioning in the youngest subjects tested, the CS presentation was lengthened to $30 \mathrm{sec}$ and three footshocks were given. Under this procedure, 8-, 12-, and 18-day-old rats were conditioned with the CS+ alone, or were conditioned with the $\mathrm{CS}+$ after exposure to the $\mathrm{CS}-$. As shown in Figure 6, 8- and 12-day-old subjects given exposure to the $\mathrm{CS}-(\mathrm{CS}-/ \mathrm{CS}+)$ acquired an aversion to the $\mathrm{CS}+$ odor, whereas 8- and 12-day-old subjects conditioned without the CS - (CS + ONLY) did not. However, the 18-day-old rats acquired an equally strong aversion to $\mathrm{CS}+$ with and without a CS - . In this situation, exposure to CS - apparently was necessary for learning about the target stimulus in the younger subjects but not in the older (18-day-old) subjects.

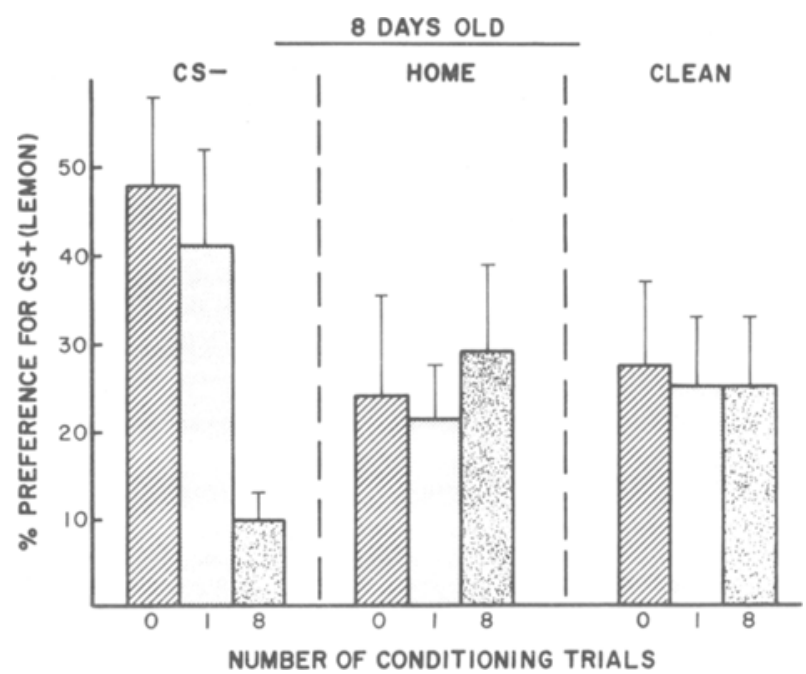

Figure 3. Mean percent preference for lemon by 8-day-olds as a function of exposure condition during $\mathrm{CS}-$ interval (CS-, home shavings, clean shavings) and number of conditioning trials $(0,1$, or 8) (adapted from Kucharski \& Spear, 1984).

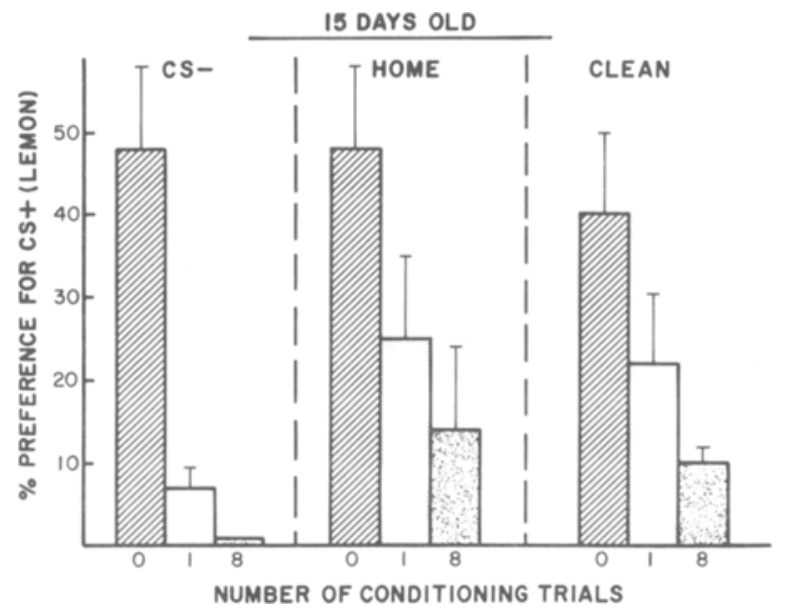

Figure 4. Mean percent preference for lemon by 15-day-olds as a function of exposure condition during $\mathrm{CS}$ - interval (CS - , home shavings, clean shavings) and number of conditioning trials $(0,1$, or 8) (adapted from Kucharski \& Spear, 1984). 


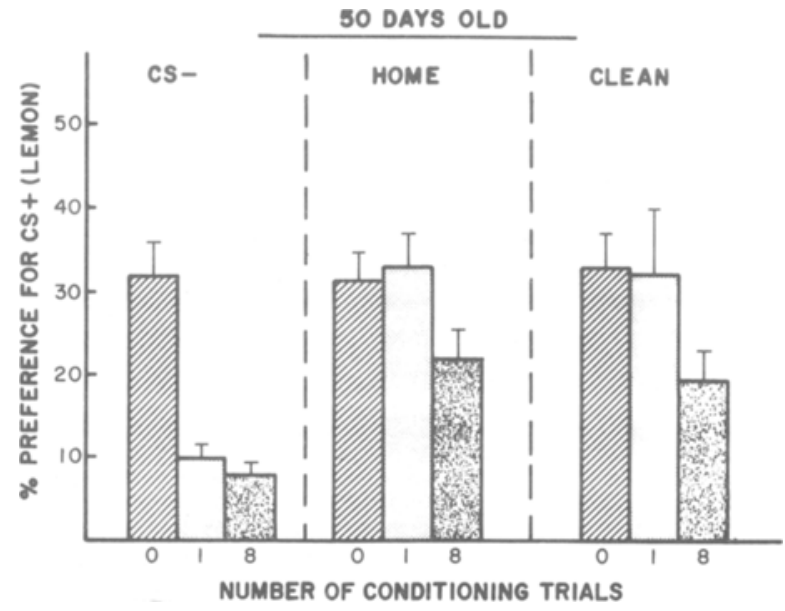

Figure 5. Mean percent preference for lemon by 50-day-olds as a function of exposure condition during $\mathrm{CS}$ - interval (CS - , home shavings, clean shavings) and number of conditioning trials $(0,1$, or 8) (adapted from Kucharski \& Spear, 1984).

\section{Generality and Characteristics of the CS- Effect}

Our next step was to determine whether the CS - effect is unique to odor conditioning. It is well known that presenting an odor is easier than getting rid of it; perhaps something peculiar about the aftereffects of odors or their actual physical dispersion in the experimental context promotes the CS - effect. A trace of CS - that lingers into the CS+ occurrence could, for example, make the problem a simultaneous, rather than a successive, discrimination. Although we commonly use different rooms for presenting different odors, we could not totally discount the possibility of odor dispersion.
We therefore conducted analogous tests that included brightness as the CS dimension, with black as the CS + and white as the CS-. The results were basically the same as with odors (Kucharski, Richter, \& Spear, 1985).

The generality of this CS - effect in classical conditioning should not be surprising. Such an effect is implied in reports from other laboratories. It seems especially evident when there is a weak biological predisposition for the animal to associate a particular CS with a US. In such cases, substantial conditioning has been obtained when the experimenters, apparently led through trial and error or "laboratory lore," have included a CS - in the training procedures. Examples include the long-delay conditioning of tactile stimuli paired with footshock by Sullivan (1979), and the conditioning of sucrose paired with footshock by Pelchat, Grill, Rozin, and Jacobs (1983).

We have confirmed the advantage of the CS - frequently in our laboratory, in a number of circumstances. Nearly always, however, the procedures have been like those described earlier. These procedures include the use of static CSs that are relatively imprecise in their prediction of the US. By this we mean that the animal is exposed to the CS, such as an odor or a brightness, for a substantial period preceding, or even following, an unconditioned stimulus. These temporal relationships are known to be less than optimal for conditioning. It seemed possible that the CS - might be effective only in such nonoptimal circumstances, when inadvertent conditioning of incidental stimuli is especially likely.

A recent study by Joseph Serwatka in our laboratory indirectly assessed this possibility. Preweanling rats were conditioned with pairings of a relatively discrete burst of odor from an olfactometer and discrete footshocks. The

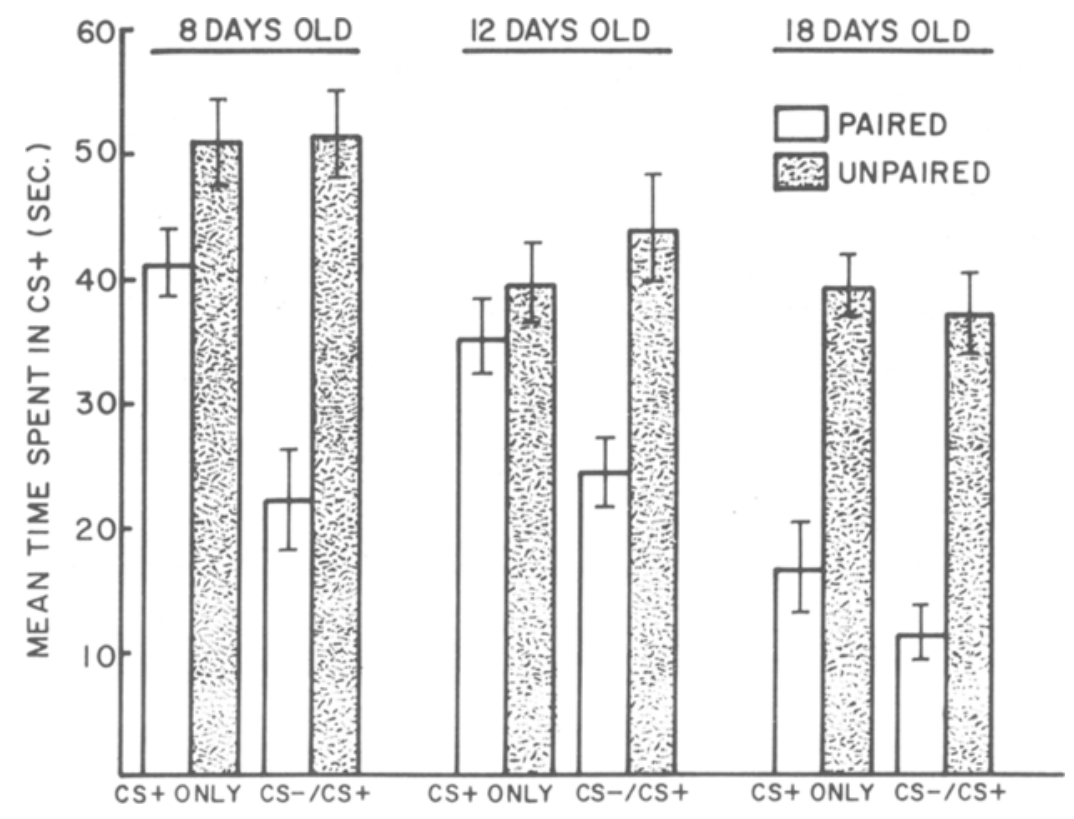

Figure 6. Mean seconds spent on CS+ during the preference test by 8-, 12-, or $18-$ day old subjects conditioned with the CS + alone (CS + ONLY) or given preconditioning exposure to $\mathrm{CS}-(\mathrm{CS}-/ \mathrm{CS}+)$. 
10-day-old rat is especially interesting for this comparison. This is the age at which Haroutunian and Campbell (1979), using a similar conditioning procedure, found negligible aversive conditioning after 30 pairings of footshock. With only 8 conditioning trials, Serwatka found that 10-day-old pups developed a substantial aversion to the $\mathrm{CS}+$, but only if they were given a $\mathrm{CS}-$ in addition to a $\mathrm{CS}+$ exposure. With only 4 conditioning trials, 15 day-old pups given a CS - developed an aversion of apparently asymptotic strength (for procedural details, see Serwatka \& Spear, 1988). This aversion to the CS + was significant relative to the animal's choice of a completely novel odor, as well as relative to the CS-. Pups not given a CS - showed no conditioning whatsoever, relative to unpaired control animals. It is possible that some feature of these conditioning procedures was "nonoptimal" (e.g., the odor serving as the CS might persist following the US), and so we cannot conclusively reject the hypothesis that the CS - effect will be strongest when conditioning procedures are weakest.

Certain characteristics of the CS - effect are notable. We have found that the order of presenting the CS- and CS + is important, although not in the way we had expected. Figure 7 illustrates the better conditioning that occurs when the CS - precedes rather than follows the $\mathrm{CS}+$, an effect replicated in many other experiments (Kucharski, Richter, \& Spear, 1985; J. S. Miller, Jagielo, Gisquet-Verrier, \& Spear, in press). We had expected the opposite order to be the more effective. With CS - immediately following the footshock, this CS might more readily acquire properties of positive affect because it signals the termination of footshock, which might in turn increase the relative aversiveness of CS + . The CS-does not generally acquire positive affect in this situation, however. In other words, although to the experimenter the $\mathrm{CS}-$ predicts safety, this does not transform the CS - into

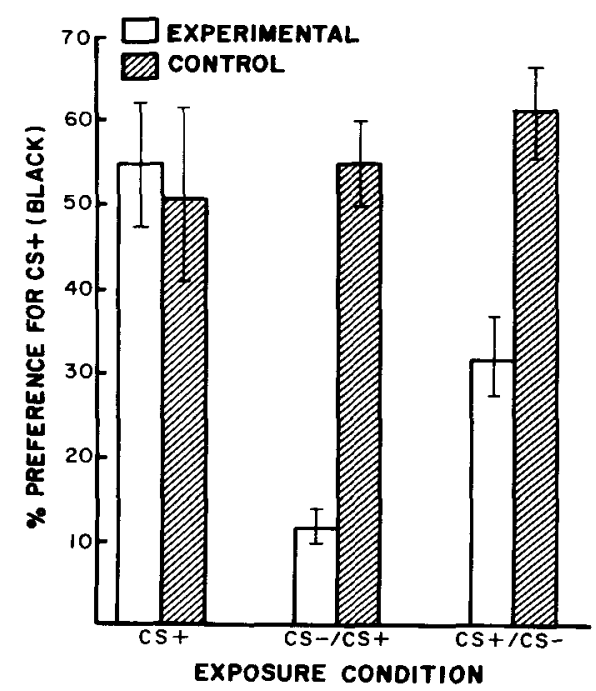

Figure 7. Mean percent preference for lemon as a function of conditioning group (experimental or control) and manipulation (CS+, $\mathrm{CS}+/ \mathrm{CS}-, \mathrm{CS}-/ \mathrm{CS}+$ ) (adapted from Kucharski, Richter, \& Spear, 1985). an item of preference as far as the animal is concerned. For rats during their second and third postnatal weeks, the CS - is quite aversive early in conditioning, despite becoming less so later on (Serwatka \& Spear, 1988).

Our data have determined no definite circumstances in which the CS - might acquire positive affect differently at different ages, but our tests have been limited. This result is consistent with the conditioned inhibition literature, which suggests that although a CS - can in some circumstances become preferred over a novel stimulus, the present discrimination learning procedures are not the optimal circumstances for such an effect (R. R. Miller $\&$ Spear, 1985). We must in any case dismiss any theory that attributes the CS - effect to the fact that the CSacquires positive affect. Not only have a large number of our experiments indicated that the $\mathrm{CS}$ - becomes aversive relative to a novel stimulus, the effect has occurred whether the test of CS + aversion is or is not conducted in the presence of the CS-.

\section{Preliminary Theories of the CS- Effect: Some Initial Tests}

Our next experiments tested rudimentary theories of the CS - effect and its ontogenetic significance. There are alternatives to the view that CS - exposure promotes selection of the CS+ as a predictor of the reinforcer. With odor-footshock conditioning, for example, presentation of the CS - , a novel odor, might increase the animal's perceptual sensitivity to other novel odors such as the $\mathrm{CS}+$ and its relationship to the US. Or, the second novel odor (CS-) might increase the animal's general arousal and thus promote learning. Such effects should not depend on where the CS - is experienced. Alternatively, if exposure to the CS - aids the animals in selecting the $\mathrm{CS}+$ odor cue as the best predictor of footshock, it would be critical that the CS- occur in the same context as the $\mathrm{CS}+$. We tested this effect of context on the CS- effect with animals that were either 15 days old or 50 days old (Kucharski \& Spear, 1984). The CS - was presented in either a clear Plexiglas context adjacent and apparently identical to that in which the CS + was presented, or in a quite different context, a black compartment located in a different part of the room. Only a single pairing of the $\mathrm{CS}+$ and US was given. The results, shown in Figure 8, were as simple as the experimental design. Relative to unpaired controls (combined in Figure 8, because they did not differ), no conditioning to the $\mathrm{CS}+$ occurred if the CS - was presented in a different context; CS + conditioning did occur if the CS - and CS + were presented in the same context. This result suggests that the CSallows the animal to select the CS + as the best predictor of the reinforcer rather than to sharpen its perception of the CS+ or to enhance its general arousal.

Another way to test whether the CS - effect is due to enhanced perception of the US is by varying the temporal relationship between the CS - and $C S+$. Suppose that the CS - precedes the CS + by a considerable length of time. The animal's perceptual dispositions may be viewed as having been set relatively permanently, so this interval 


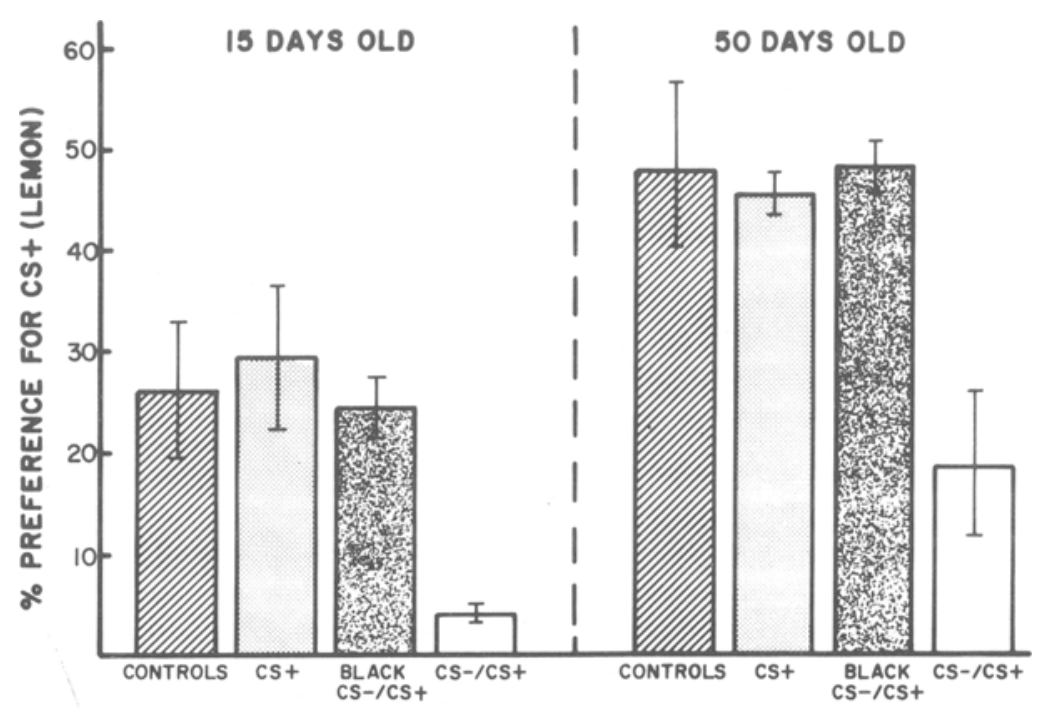

CONDITIONING GROUP

Figure 8. Mean percent preference for lemon as a function of age (15 or 50 days of age) and conditioning group [controls, $\mathrm{CS}+$, black (different context for $\mathrm{CS}-$ ) $\mathrm{CS}-/ \mathrm{CS}+$, CS-/CS+] (adapted from Kucharski, Richter, \& Spear, 1985 ).

between the CS - and CS + should have little effect in terms of this perceptual theory. Yet the memory for the occurrence of the CS - in a particular context, the critical determinant for the stimulus selection notion, should be less accessible at the time of the CS + , and in this view a longer interval between the $\mathrm{CS}-$ and $\mathrm{CS}+$ should decrease conditioning to the $\mathrm{CS}+$. The assumptions underlying these alternative predictions are not as strong as we should like, but they lead to an experiment that also is useful for other reasons, as will become evident.

The experiment was quite simple. First, rats were given as their CS - a single, 20-sec exposure to a white chamber where no footshock was administered. After either few seconds, several minutes, or several hours had passed, they were given their CS + , a 20-sec exposure to the black chamber where footshock was administered. The intervals between the CS - and CS + were $2 \mathrm{sec}, 1 \mathrm{~h}, 6 \mathrm{~h}$, $12 \mathrm{~h}$, or $24 \mathrm{~h}$. The effects were compared for adults and preweanlings (16-17 days postnatal). We used brightness rather than odor as the CS dimension in order to have better control over the temporal characteristics of the CSs (e.g. , this eliminated the possibility that the CS- odorant might cling to the animal itself and be detected after CS exposure).

Figure 9 shows that the interval between $\mathrm{CS}-$ and $\mathrm{CS}+$ made a substantial difference. Learning about the CS+ was less, the longer the interval since presentation of the CS - (unpaired control animals showed no changes in brightness preference with these intervals; see Figure 10). When the interval was as long as $\mathbf{2 4} \mathbf{~ h}$, it was as if presentation of the CS - was totally forgotten-there was no measurable conditioning. Conditioning did occur for adults if the interval between CS - and CS + was $12 \mathrm{~h}$ or less, but loss of the effect of the CS - was much more rapid for preweanlings (see Figure 11). The preweanlings showed no conditioning to the $\mathrm{CS}+$ if the interval since CS - presentation was as long as $1 \mathrm{~h}$. A subsequent experiment identified the course of forgetting within this $1 \mathrm{~h}$ period: either a 20 - or a $40-\mathrm{min}$ interval could be tolerated by preweanlings, but not $60 \mathrm{~min}$. This is as would be expected if we are dealing with a memory effect, in view of the growing evidence that preweanlings forget more rapidly than adults over short as well as long intervals (Moye \& Rudy, 1987; Spear, 1978, 1984b).

\section{Use of the CS - Effect as a Test}

\section{of Short-Term Retention}

Recently we have used the CS - effect for measurement of short-term retention (J. S. Miller, Jagielo, \& Spear, in press; Miller \& Spear, in press). In one such study, 8- and 12-day-old subjects received exposure to an odor that was not paired with footshock (CS-), prior to a single pairing of a second odor (CS+) with footshock. We varied the length of the delay imposed between exposure to the CS - and CS + . Since expression of a conditioned aversion to the $\mathrm{CS}+$ is dependent on exposure to the CS - , the memory for the CS- could be inferred to the extent that the rats avoided the subsequently presented CS + . For other subjects, the delay was imposed between the conditioning treatment and the test for the conditioned aversion. In this way it was possible to examine the memory for "incidental" (CS-) versus target $(\mathrm{CS}+)$ elements of the conditioning episode.

The results of this study, presented in Figure 12, illustrate two points. First, for both age groups, the forgetting of incidental elements of the conditioning episode (CS-) proceeded more rapidly than did any loss of the memory for an event (CS+) paired with an aversive US. Second, forgetting for both the incidental and target elements of the conditioning episode was more rapid for the 


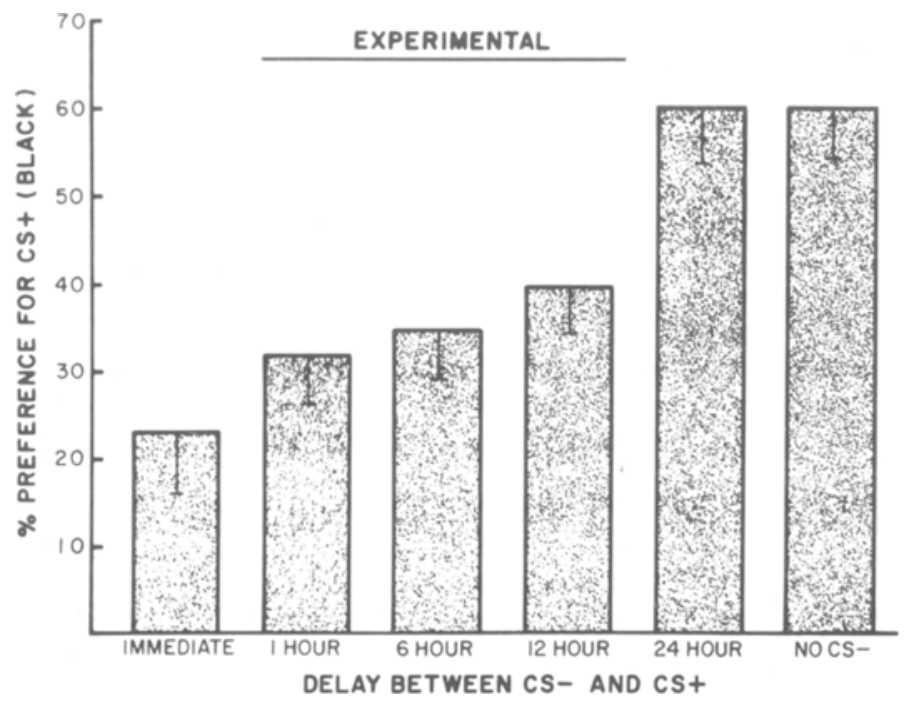

Figure 9. Mean percent preference for the black compartment (time spent in black compartment/time spent in black compartment + time spent in white compartment) as a function of delay between $\mathrm{CS}-$ and $\mathrm{CS}+$ for the adult experimental rats (paired CS+ and US) (adapted from Kucharski, Richter, \& Spear, 1985).

younger subjects. This illustrates how the $\mathrm{CS}-$ effect may be utilized to examine ontogenetic differences in the shortterm retention of various elements of a conditioning episode.

\section{Summary, Application, and Extension}

\section{of the Basic Evidence}

So far, we have isolated several characteristics of the effects of a "CS -" (i.e., a nonreinforced value of the same sensory dimension as the $\mathrm{CS}+$ ). The facts can be listed simply:
(1) Exposure to the CS - permits (more rapid) conditioning in rats 8-10 days old, and perhaps for associations that are not biologically "prepared." (2) The CS - also can speed conditioning in older animals. (3) The CSis ineffective in a context different from that of the CS + . (4) The CS - is more effective if it precedes rather than follows the CS+. (5) The CS - is ineffective if it precedes the CS + by a substantial interval, which might be described as "forgetting of the CS-." (6) Forgetting of the $\mathrm{CS}-$ is more rapid in younger animals. (7) The CS-

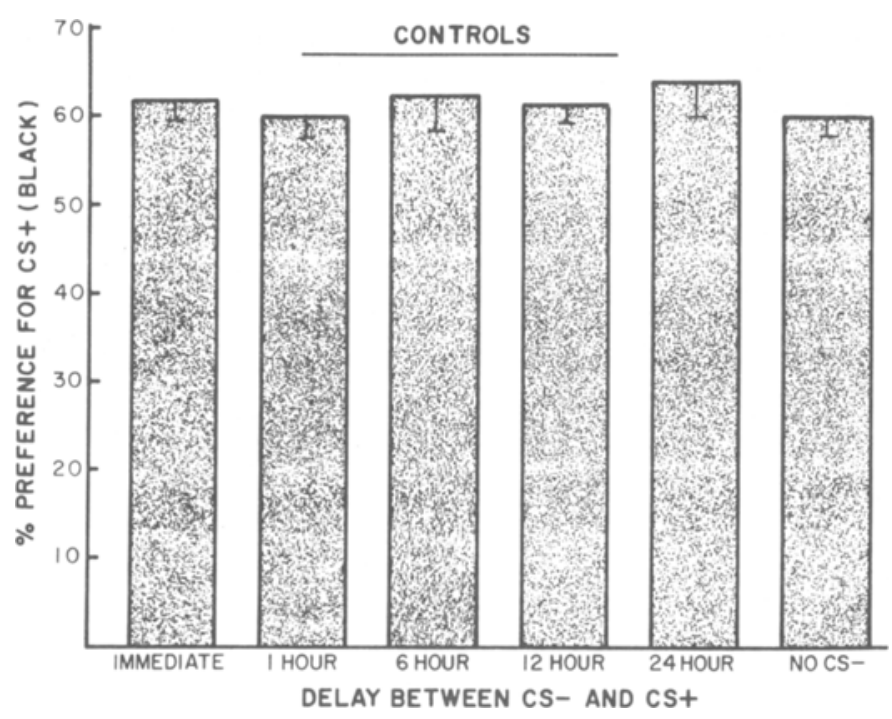

Figure 10. Mean percent preference for the black compartment as a function of the delay between CS - and CS + for the adult control (unpaired CS+; US delivered 1 h prior to CS+) subjects (adapted from Kucharski, Richter, \& Spear, 1985). 


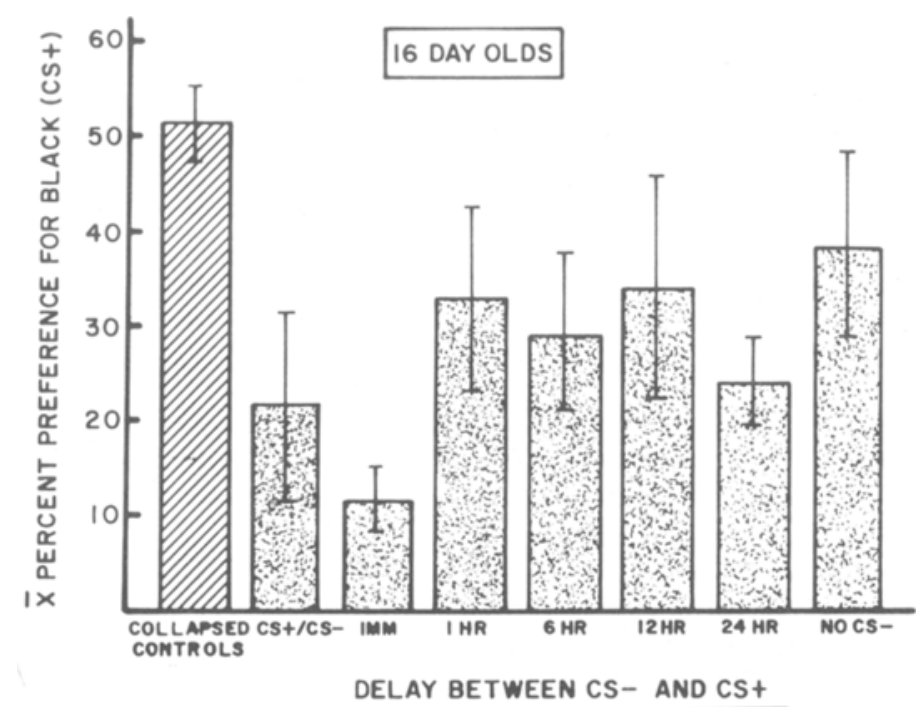

Figure 11. Mean percent preference for the black compartment as a function of delay between CS - and CS + (for paired groups) and control condition (unpaired; collapsed over delays between $\mathrm{CS}-$ and $\mathrm{CS}+$ ) for 16-day-old rats (adapted from Kucharski, Richter, \& Spear, 1985).

effect on CS + conditioning seems to be independent of $\mathrm{CS}-$ conditioning. (8) The effect of the CS - on CS + preference seems independent of whether CS + conditioning is aversive or appetitive (a point to be illustrated in a moment).

Affective conditioning in very young rats clearly benefits from presentation of a CS - as well as a CS +. Conditioning in the absence of a CS - may proceed given enough pairings of only a CS + and a US of footshock, but in some circumstances, conditioning on a single trial seems to require a $\mathrm{CS}-$ even for adult rats. Provided that the associative requirements for conditioning are met, it therefore does not appear that the infant rat is incapable of forming associations between odors and footshocks. This does not answer why odor aversions can be acquired more rapidly by pairing the odor with toxicosis or shock to the gut in neonates without need for a CS - (as found by Haroutunian \& Campbell, 1979), or why taste aversions can similarly be acquired with a single pairing of a flavor with toxicosis during the first postnatal week (Hoffmann, Molina, Kucharski, \& Spear, 1987; Molina, Hoffmann, \& Spear, 1987), but these effects are related to a different issue.

The advantage of the CS - seems to be in the information it conveys as to the best predictor of the reinforcer, rather than in its being a means for sharpening the perception of the CS+ or increasing arousal. Finally, memory of the CS - must be active at the time of the CS+ if it is to be effective, and forgetting of this memory proceeds more rapidly in younger animals.

By applying the CS - rule, we have solved an experimental paradox involving the consequences of isolation from home in the preweanling rat. It has been known for some time that when the preweanling rat is removed from its home, particularly during the early part of the third postnatal week, it reacts with violent distress within a very few minutes. Its heart rate increases by $25 \%$; its general activity doubles or triples; its ultrasounding increases 5 or 6 times. These are the same kinds of behaviors that occur when the animal is placed into an aversive situation, so one might think that isolation from home

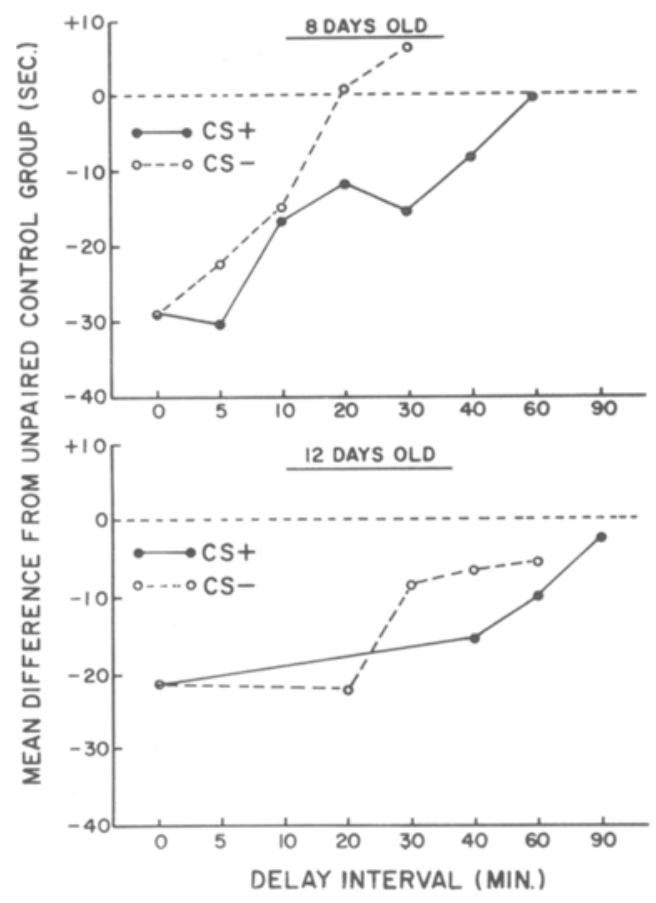

Figure 12. Mean difference in seconds spent in CS + between paired subjects and unpaired control subjects, as a function of delay interval between conditioning and testing (solid circles) or between CS- and CS+ (open circles). Larger negative scores indicate stronger retention; 0 indicates no retention. 
is aversive. Yet in a large number of experiments that have involved novel odors paired with isolation from home for various lengths of time, from a few minutes to many hours, no acquired aversion to these odors has been found. On the contrary, the typical result is an increased preference for the odor paired with isolation (Alberts, 1981; Caza \& Spear, 1984; Galef \& Kaner, 1980; Leon, Galef, \& Behse, 1977; Wigal, Kucharski, \& Spear, 1984). Together with Gregory Smith we found, however, that if the isolated animal is provided a CS - odor signaling nonisolation and a CS + odor signaling isolation, the odor associated with a 4-h period of isolation becomes absolutely aversive. Without the $\mathrm{CS}-$ it becomes a preferred odor. This acquired aversion, shown in Figure 13, is substantial in rats 9,16 , or 23 days of age, but it disappears when the rat approaches the age of natural weaning (about 30 days), indicating that isolation can be an effective US for animals younger, but not older, than $\mathbf{3 0}$ days of age (Smith, Kucharski, \& Spear, 1985).

In our tests with isolation as the US, we were surprised to find little acquired preference for the odor explicitly paired with home. This was, however, our first test of the CS - effect with appetitive conditioning, and this case may be "appetitive" only in contrast to the aversive isolation. Is the CS - effect limited to circumstances of aversive conditioning? An experiment by Hoffmann and Spear (1984) addressed this possibility. For 12-day-old rats, Hoffmann paired a discrete burst of odor from an olfactometer with a $15 \%$ sucrose solution. The sucrose solution was infused for $5 \mathrm{sec}$ into the pup's mouth through an implanted cannula. The CS + odor was paired with the sucrose solution; some pups were also given the CS- odor paired with no sucrose solution, and some were not. When preference for the CS+ was measured against that for a novel odor and compared among animals given or not given a CS - , Hoffmann found that CS + preference was enhanced among those animals given a CS - . The CS - effect apparently can occur in appetitive circumstances, although the importance and generality of the effect for appetitive conditioning is uncertain.

\section{Summarizing Comment on Theory and Application}

A final step is to summarize some alternative theories for explaining the influence of the CS-. It is significant that we are focusing on affective conditioning manifested in the animal's preference for being close to or far from a particular stimulus. Other modes of expressing conditioning to the CS + may be less dependent on a CS-, and certainly there are cases of affective conditioning that do not require an explicit CS - (e.g., conditioned taste aversion). Whether there is in such conditioning an implicit CS - is a matter for consideration. These points merely illustrate that, like theories of conditioning in general, theories of the CS - effect eventually must take into account the constraints exerted by the requirements of expression (Spear, 1984a).

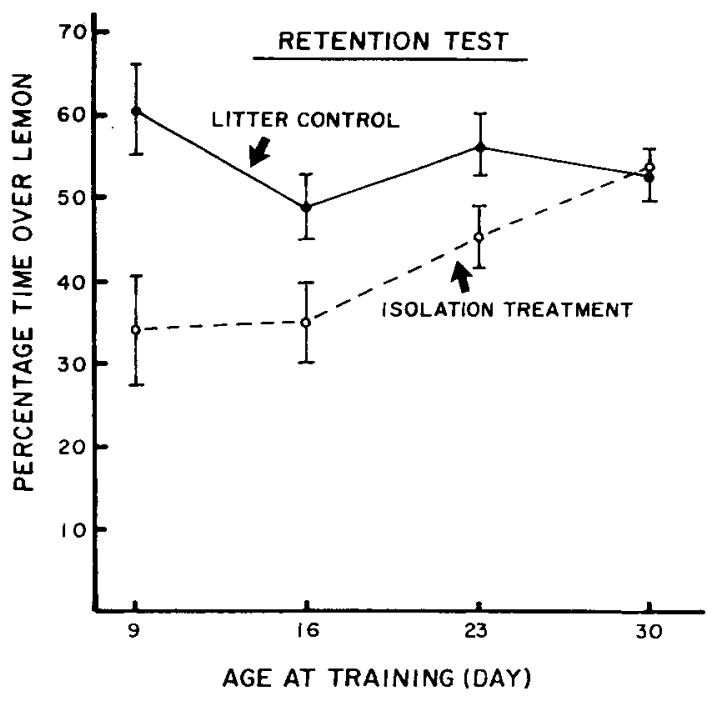

Figure 13. Mean percent time over lemon (time spent over lemon/time spent over lemon + time spent over peppermint), the CS+ odorant, paired with isolation in the "isolation treatment" group, as a function of age and conditioning group (adapted from Smith, Kucharski, \& Spear, 1985).

Three general theories. We may consider in the meantime three general theories about the influence of the CS - .

(1) For the first theory, two opposing effects of an exposure to the CS + are emphasized. The first effect is enhanced preference for the particular value of the CS dimension represented by the CS + , based probably on a "decreased neophobia" for that value relative to other values of that dimension. In the case of odors, a single presentation in the absence of a reinforcer does yield this type of learning (Caza \& Spear, 1984). For rats as young as 10 days old, for instance, a 3-min exposure to a novel odor increases preference for that odor over a completely novel odor. This induced preference is not increased very much with exposures of 30,60 , or $90 \mathrm{~min}$, and simple exposure to an odor at durations shorter than $3 \mathrm{~min}$ might be sufficient for learning about it. Also, if presented a pair of odors simultaneously for only $3 \mathrm{~min}$, rats as young as 10 days postnatal acquire an association between them (Brandt, 1983; Spear \& Kucharski, 1984a, 1984b). This first effect of enhanced preference through familiarity is presumably neutralized by unpaired control conditions that include an equal opportunity for familiarity. Yet it remains possible that the simultaneous presentation of the aversive (footshock) US and CS + in the paired experimental condition promotes familiarity with the CS + and a consequential increase in preference (Camp \& Rudy, 1988).

The second effect of CS+ exposure is of course a decrement in preference for this $\mathrm{CS}+$ and all of its correlates (including other values of the CS dimension) due to the pairing of these events with footshock.

Our data indicate that the first effect-enhanced neophobia-linked preference-builds up rapidly, whereas 
the decreased preference due to the pairing with an aversive footshock is acquired more slowly but with greater magnitude of effect. With limited exposure to the $\mathrm{CS}+$, the balance of these two consequences of this experience would therefore seem to be "no conditioning" in the sense of no change in net preference. This is precisely what was found for a single presentation of the $\mathrm{CS}+$, at all ages tested.

In this theory, then, the CS - could aid CS + conditioning by interfering with the decrease in neophobia for (i.e., increase in familiarity with) the CS + , or by facilitating the association between the CS + and footshock. Interference with CS + familiarity seems unlikely. It seems more reasonable that the $\mathrm{CS}-$ has its major effect by facilitating the association of the CS + with shock, probably by identifying irrelevant and unpredictive stimuli that are less predictive than the $\mathrm{CS}+$. On this basis it would be surprising if nothing aversive were learned by the 10day-old about an odor paired several times with footshock, but that is what our data indicate. One possibility is that in such young rats, the footshock induces retrograde amnesia for the odor paired with it (see Rudy, 1985). That this is not so is shown by our studies in which a pair of odors is presented simultaneously, followed by a footshock, in tests of potentiation and overshadowing (Spear \& Kucharski, 1984a, 1984b). As far as we can tell, learning of the association between those two odors remains intact, indicating no retrograde amnesia. This first theory, therefore, holds some promise but also poses a few problems.

(2) A similar theory focuses on the change in the affect elicited by the CS + and the expression of this affective change. The CS + might acquire no change in affect until it is differentiated, by virtue of exposure to a CS -, from irrelevant and unpredictive stimuli. Alternatively, the CS +, along with all irrelevant or redundant stimuli present at the time of the footshock, might acquire an equivalent change in affect that is not expressable in most preference tests. The fundamental problem in both cases is for the animal to pick out the $\mathrm{CS}+$ from the "background."

(3) A third possibility is that exposure to the CSprimes the subject for attention to the CS + and for learning about it. This seems verified by the superiority of the CS,- CS + order in conditioning (compared with the $\mathrm{CS}+, \mathrm{CS}-$ order) and by the weakening of conditioning with longer intervals between the CS - and $\mathrm{CS}+$. Yet direct confirmation of such "priming" is missing.

We must be indecisive here. It is difficult to choose among these or other theories without more data.

Application. Basic conditioning can be analyzed usefully with very simple procedures; when we must assess memory in the infant rat, which can have limited sensory input and few effective operant behaviors, simplicity in procedure is forced upon us. There is an immediate application from this approach in studies of the neurophysiological basis of memory that require a simple procedure for establishing learning within a single trial, and a test with limited motor requirements: for simple affective conditioning, the presence of a CS - can substantially enhance CS + conditioning or produce CS + conditioning that is otherwise absent. The procedures for such conditioning are extremely simple; they are more readily instrumented and completed than even the one-trial passive avoidance task, and they require even less time for implementation. And, this form of conditioning has the advantage of more stimulus control and less susceptibility to response artifacts than tasks such as passive avoidance. It provides, in short, a useful tool for studying the neurophysiological basis of learning and memory.

\section{REFERENCES}

Alberts, J. R. (1981). Ontogeny of olfaction: Reciprocal roles of sensation and behavior in the development of perception. In R. N. Aslin, J. R. Alberts, \& M. R. Peterson (Eds.), The development of perception: Psychobiological perspectives: Vol. 1. Audition, somatic perception and the chemical senses (pp. 322-358). New York: Academic Press.

AMSEL, A. (1986). Developmental psychobiology and behavior theory: Reciprocating influences. Canadian Journal of Psychology, 40, 311-314.

AmSEL, A., Stanron, M. (1980). Ontogeny and phylogeny of paradoxical reward effects. In J. S. Rosenblatt, R. A. Hinde, R. Beer, \& M. Busnel (Eds.), Advances in the study of behavior (pp. 227-274). Academic Press: New York.

BRANDT, J. P. (1983). The influence of neonatal administration of ACTH 4-9 analog on stimulus selection in developing rat. Unpublished master's thesis, State University of New York at Binghamton.

BRYAN, R. G. (1979). Retention of odor-shock conditioning in neonatal rats: Effects of distribution of practice. Unpublished doctoral dissertation. Rutgers University, New Brunswick, NJ.

CAMP, L. L., \& RUDY, J. W. (1988). Changes in the categorization of appetitive and aversive events during postnatal development of the rat. Developmental Psychobiology, 21, 25-42.

CAMPBell, B. A. (1967). Developmental studies of leaming and motivation in infra-primate mammals. In H. W. Stevenson, E. H. Hess, \& R. H. Rheingold (Eds.), Early behavior: Comparative and develop mental approaches (pp. 43-72). New York: Wiley.

Camprell, B. A., \& Spear, N. E. (1972). Ontogeny of memory. Psychological Review, 79, 215-236.

CAZA, P. A. (1984). Noradrenergic influences on blocking: Interactions with development. Pharmacology, Biochemistry \& Behavior, 21, 9-17.

Caza, P. A., Spear, N. E. (1984). Short-term exposure to an odor increases its subsequent preference in preweanling rats: A descriptive profile of the phenomenon. Developmental Psychology, 17, 407-422.

Collier, A. C., \& Bolles, R. C. (1979). The ontogenesis of defensive reactions to shock in preweanling rats. Developmental Psychobiology, 13, 141-150.

Galef, B. G., JR., Kaner, H. C. (1980). Establishment and maintenance of preference for natural and artificial olfactory stimuli in juvenile rats. Journal of Comparative \& Physiological Psychology, 94, 588-595.

GARNER, W. R. (1974). The processing of information as structure. Hillsdale, NJ: Erlbaum.

Garrud, P., Rawlins, J. N. P., Mackintosh, N. J., Goodall, G., Cotton, M. M., \& Feldon, J. (1984). Successful overshadowing and blocking and hippocampectomized rats. Behavioral Brain Research, 12, 39-53.

Haroutunian, V., \& Campelel, B. A. (1979). Emergence of interoceptive and exteroceptive control of behavior in rats. Science, 205 , 927-929.

HinderLiter, C. F., \& Misanin, J. R. (1988). Weanling and senescent rats process simultaneously-presented odor and taste differently than young adults. Behavioral \& Neural Biology, 49, 112-117.

hoffmann, H., Moluna, J. C., Kucharski, D., \& Spear, N. E. (1987) Further examination of ontogenetic limitations on a conditioned taste aversion. Developmental Psychobiology, 20, 455-463. 
Hoffmann, H., \& SPEAR, N. E. (1984). Behavioral indices of a conditioned discrimination in 12-day-old rats. Paper presented at meetings of the Eastern Psychological Association, Baltimore, Maryland.

HoffmanN, H., \& SPEar, N. E. (1988). Ontogenetic differences in conditioning of an aversion to a gustatory CS with a peripheral US. Behavioral \& Neural Biology, 50, 16-23.

Infurna, R. N., Steinert, P. A., \& Spear, N. E. (1979). Ontogenetic changes in the modulation of taste aversion learning by home environmental cues. Journal of Comparative \& Physiological Psychology, 93, 1097-1108.

KAIL, R., SPEAR, N. E. (Eds.) (1984). Comparative perspectives in memory development. Hillsdale, NJ: Erlbaum.

Kraemer, P. J., Lariviere, N. A., \& Spear, N. E. (1988). Expression of a taste aversion conditioned with an odor-taste compound: Overshadowing is relatively in weanlings and decreases over a retention interval in adults. Animal Learning \& Behavior, 16, 164-168.

Kucharski, D., Richter, N. G., \& SPEAR, N. E. (1985). Conditioned aversion is promoted by memory of CS-. Animal Learning \& Behavior, 13, 143-151.

Kucharski, D., \& Spear, N. E. (1984). Conditioning of aversion to an odor paired with peripheral shock in the developing rat. Developmental Psychobiology, 17, 465-480.

Kucharski, D., \& Spear, N. E. (1985). Potentiation and overshadowing in preweanling and adult rats. Journal of Experimental Psychology: Animal Behavior Processes, 11, 15-34.

Leon, M., Galef, B. G., JR., \& Behse, J. H. (1977). Establishment of pheromonal bonds and diet choice by odor pre-exposure. Physiology \& Behavior, 18, 387-391.

MACKINTOSH, N. J. (1974). The psychology of animal learning. London: Academic Press.

Markiewicz, B., Kucharskı, D., \& Spear, N. E. (1986). Ontogenetic comparison of memory for Pavlovian conditioned aversions in temperature, vibration, odor or brightness. Developmental Psychobiology, 19, 139-154.

Miller, J. S., Jagielo, J., Gisquet-Verrier, P., \& Spear, N. E. (in press). Backward excitatory conditioning can determine the role of the $\mathrm{CS}-$ in aversion learning. Learning \& Motivation.

Miller, J. S., Nonneman, A. J., Kelly, K. S., Neisewander, J. L., \& ISAAC, W. L. (1986). Disruption of neophobia, conditioned odor aversion, and conditioned taste aversion in rats with hippocampal lesions. Behavioral \& Neural Biology, 45, 240-253.

Miller, R. R., \& SPEAR, N. E. (Eds.) (1985). Information processing in animals: Conditioned inhibition. Hillsdale, NJ: Erlbaum.

Miller, J. S., \& SPEAR, N. E. (in press). Ontogenetic differences in short-term retention of Pavlovian conditioning. Developmental Psychobiology.

Molina, J. C., Hoffmann, H., \& Spear, N. E. (1987). Conditioning of aversion to alcohol orosensory cues in 5- and 10-day old rats: Subsequent reduction in alcohol ingestion. Developmental Psychobiology, $19,175-183$

MoYe, T. B., \& RUDY, J. W. (1987). Ontogenesis of trace conditioning in young rats: Dissociation of associative and memory processes. Developmental Psychobiology, 20, 405-414.

Pelchat, M. L., Grill, H. J., Rozin, P., \& Jacobs, J. (1983). Quality of acquired responses to taste by Rattus norvegicus depends on type of associated discomfort. Journal of Comparative Psychology, 97, 140-153.

Rescorla, R. A., \& Wagner, A. R. (1972). A theory of Pavlovian conditioning: Variations in the effectiveness of reinforcement and nonreinforcement. In A. H. Black \& W. F. Prokasy (Eds.), Classical conditioning II (pp. 64-99). New York: Appleton-Century-Crofts.

RuDY, J. W. (1985). An appreciation of higher-order conditioning and blocking. In M. Commons, R. J. Herrnstein, \& A. R. Wagner (Eds.), Quantitative analyses of behavior: Vol. 3. Acquisition. Cambridge: Ballinger.

Schmajuk, N. A., Spear, N. E., \& IsaACSON, R. L. (1983). Absence of overshadowing in rats with hippocampal lesions. Physiological Psychology, 11, 59-62.

SerwatKa, J., \& SpEar, N. E. (1988). Acquisition and retention of separate elements of a conditioned olfactory discrimination in preweanling rats. Developmental Psychobiology, 21, 145-159.

Smith, G. J., KucharsKi, D., \& SPEar, N. E. (1985). Ontogenetic differences in the conditioning of an odor aversion using isolation from the home nest environment as the conditioned stimulus. Developmental Psychobiology, 18, 421-434.

Smith, G. J., \& Spear, N. E. (1978). Home environmental effects on withholding behaviors and conditioning in infant and neonatal rats. Science, 202, 327-329.

Solheim, G. S., Hensler, J. G., \& SPEar, N. E. (1980). Age-dependent contextual effects on short-term active avoidance retention in rats. Behavioral \& Neural Biology, 30, 250-259.

SPEAR, N. E. (1978). Processing memories: Forgetting and retention. Hillsdale, NJ: Erlbaum.

SPEAR, N. E. (1979). Memory storage factors in infantile amnesia. In G. Bower (Ed.), The psychology of learning and motivation (Vol. 13, pp. 91-154). New York: Academic Press.

SPEAR, N. E. (1984a). Behaviors that indicate memory: Levels of expression. Canadian Journal of Psychology, 38, 348-367.

SPEAR, N. E. (1984b). Ecologically determined dispositions control the ontogeny of learning and memory. In R. Kail \& N. E. Spear (Eds.), Comparative perspectives on the development of memory (pp. 325328). Hillsdale, NJ: Erlbaum.

SPEAR, N. E., \& CAMPBell, B. A. (EDs.) (1979). The Ontogeny of learning and memory. Hillsdale, $\mathrm{NJ}$ : Erlbaum.

Spear, N. E., Kraemer, P. J., Molina, J. C., \& Smoller, D. E. (1988). Developmental change in learning and memory: Infantile disposition for "unitization." In J. Delacour \& J. C. S. Levy (Eds.), Systems with leaming and memory abilities: Proceedings of the Workshop held in Paris, June 15-19, 1987 (pp. 27-52). Elsevier/North Holland Press.

SPEAR, N. E., \& KucharsKI, D. (1984a). Ontogenetic differences in the processing of multi-element stimuli: Potentiation and overshadowing. In H. Roitblat, T. Bever, \& H. Terrace (Eds.), Animal cognition (pp. 545-568). Hillsdale, NJ: Erlbaum.

SPEAR, N. E., \& KuCharSKI, D., (1984b). Ontogenetic differences in stimulus selection during conditioning. In R. Kail \& N. E. Spear (Eds.), Comparative perspectives on the development of memory (pp. 227-252). Hillsdale, NJ: Erlbaum.

Spear, N. E., Kucharski, D., \& Hoffmann, H. (1985). Contextual influences on conditioned tasted aversion in the developing rat. In N. Braveman \& P. Bronstein (Eds.), Experimental assessments and clinical applications of conditioned food aversions (pp. 42-53). New York: New York Academy of Sciences.

Spear, N. E., \& Molina, J. C. (1987). The role of sensory modality in the ontogeny of stimulus selection. In N. Krasnegor, E. M. Blass, M. A. Hofer, \& W. P. Smotherman (Eds.), Perinatal development: A psychobiological perspective (pp. 83-110). Orlando, Florida: Academic Press.

Sullivan, L. (1979). Long-delay learning with exteroceptive cue and exteroceptive reinforcement in rats. Australian Journal of Psychology, 31, 21-32.

W AGNER, A. R. (1981). SOP: A model of automatic memory processing in animal behavior. In N. E. Spear \& R. R. Miller (Eds.), Information processing in animals: Memory mechanisms (pp. 5-48). Hillsdale, NJ: Erlbaum.

Wigal, T., Kucharski, D., \& Spear, N. E. (1984). Familiar contextual odors promote discrimination learning in preweanling but not in older rats. Developmental Psychobiology, 17, 555-570.

(Manuscript received May 28, 1986; revision accepted for publication June $17,1987$. 